\title{
CORRIGENDUM
}

\section{Bortezomib and donor lymphocyte infusion in multiple myeloma relapsed after allo-SCT does not result in durable remissions}

IA Hoevenaren, LFD van Vulpen, H Levenga, MC Minnema and R Raymakers

Bone Marrow Transplantation (2011) 46, 322; doi:10.1038/bmt.2010.111; published online 26 April 2010

Correction to: Bone Marrow Transplantation (2011) 46, 319-321; doi:10.1038/bmt.2010.56

should have been IA Hoevenaren. The correct list is shown above.

Since the publication of this article an error has been identified in one of the authors' names. A Hoevenaren

The authors would like to apologize for any confusion this may have caused. 